\title{
Two-body wear of occlusal splint materials against different antagonists
}

\author{
Kubra Yildiz Domanic ${ }^{*}$ Yilmaz Umut Aslan and Yasemin Ozkan
}

\begin{abstract}
Background: This study aimed to demonstrate that the material of the occlusal splint can be chosen according to the needs of individual patients and contribute to the knowledge of the wear rate of these materials.

Methods: In this study, four occlusal splint materials (Sr Ivocap Heat Cured, Valplast, SR Ivocap Elastomer and Eclipse) and three antagonists (natural tooth enamel, inCoris TZI and IPS e.max Press ceramic materials) were used. Each wear test was performed using a chewing simulator ( $n=16$; test load: $50 \mathrm{~N}$; number of cycles: 10,000, 20,000 and 30,000; continuous rinsing with water at $30^{\circ} \mathrm{C}$ for the wet condition). The Shapiro Wilk test was used for normal distribution suitability. Antagonist on average wear quantities both main effects and interactions of material, cycle and condition factors were investigated by Univariate variance analysis. Multiple comparisons were examined using the Games-Howell test.

Results: There was a statistically significant effect of the difference in materials on the amount of wear $(p<0.001)$. Furthermore, there was a statistically significant difference among the mean values of all materials $(p>0.001)$. The highest mean value was obtained with Eclipse $\left(0,318 \mathrm{\mu m}^{3}\right)$, and the lowest mean value was obtained with Valplast $\left(0,134 \mu \mathrm{m}^{3}\right)$.
\end{abstract}

Conclusion: Our study found differences in the in vitro wear rate among various occlusal splint materials.

Keywords: Occlusal splints, Two-body wear, Splint materials

\section{Background}

Occlusal splints are commonly used to protect dentition from parafunctional forces. Occlusal splints are often preferred for treating and preventing temporomandibular joint disorders (TMD) a condition with varying degrees of presentation and severity [1]. Occlusal splints are removable appliances that are usually fabricated from acrylic resin for use in the upper or lower jaw [2]. The wear of occlusal splints over time is of clinical concern. The material type of occlusal splint or the antagonist surface influence the wear rate; but how long and how much? A variety of materials are currently used for fabricating occlusal splints. Most manufacturers report

\footnotetext{
*Correspondence: drkubrayildiz@gmail.com

Department of Prosthodontics, Dentistry Faculty, University of Marmara, Basibuyuk, Maltepe, Istanbul, Turkey
}

that these materials are chemically related to methacrylates $[3,4]$. Four different materials are generally used to fabricate splints for TMD treatment, i.e., urethane dimethylacrylate, methyl methacrylate, polymethyl methacrylate, and polyamide [4].

Researchers have identified five different types of wear and have described the wear mechanisms of these materials. Wear in these contact types is described as sliding wear, rolling wear, impact wear, fretting wear, or slurry wear [5]. These descriptions of wear are all technical and based on the appearance of the contact type. They do not represent wear mechanisms in a scientific way [5]. Wear has been recognized as meaning the phenomenon of material removal from a surface due to interaction with a mating surface [6]. Two-body wear can be defined as the surface sweeping of the material in direct contact with another substance. The occasional presence of an 
abrasive particle or liquid during wear between these two surfaces is defined as three-body wear [3]. Most clinical data on wear focus on restorative materials and artificial teeth [4-9]. Limited data on the wear characteristics of interocclusal devices and splints are available $[10,11]$. Casey et al. [11] focused on the in vitro wear of various orthodontic appliance materials used in the fabrication of splints using a load of $9.1 \mathrm{~kg}$ for 2500 reciprocal cycles. We were motivated to conduct this study, because the previous study used extremely few cycles. Moreover, there have been advancements in the materials used to fabricate splints mainly used for TMD treatment.

The aim of present study was to identify and compare the wear characteristics of 3 different antagonists on 4 different materials used in occlusal splint fabrication using predefined and standardized conditions. Based upon this wear knowledge, practitioners are able to more reliably choose the appliance material necessary for their various patients. The null hypothesis of this study was that there are no differences between the groups studied, while evaluating the volumetric loss resulting from wear.

\section{Methods}

Disc-shaped specimens with a diameter of $16 \mathrm{~mm}$ and thickness of $3 \mathrm{~mm}$ were fabricated to quantify the wear of different materials. Sixteen specimens of each splint material were tested. The composition of the materials and the associated information from the manufacturers are listed in Table 1.

The test surfaces of all specimens were smoothened using waterproof silicon carbide grinding papers of 220, 500, 800, and 1200 grit (Struers A/S, Ballerup, Denmark). The specimens were finished with a rag wheel and fine pumice slurry, followed by the application of a universal polishing paste (Ivoclar Vivadent AG, Schaan, Liechtenstein). The specimens were finished with a cloth and thin pomade, followed by polishing paste application. All specimens were stored in distilled water at $25^{\circ} \mathrm{C}$ for 2 weeks before testing. The specimen surfaces was polished by a single operator using an OptraFine ceramic polishing system (Ivoclar Vivadent AG, Schaan, Liechtenstein), based on the manufacturer's recommendations. OptraFine $\mathrm{F}$ finishers (light blue) were used with water to smoothen the ceramic surface. OptraFine $\mathrm{P}$ polishers (dark blue) were used with water to polish the ceramic surface. Finally, the OptraFine HP high polishing brush and paste were used without water to obtain a highluster gloss on the ceramic surface.

InCoris TZI C (Sirona Dental Systems GmbH, Bensheim, Germany) and IPS e.max Press (Ivoclar Vivadent AG, Schaan, Liechtenstein) specimens were fabricated as spheres with a height of $5 \mathrm{~mm}$ and a diameter of $4 \mathrm{~mm}$ according to the manufacturer's manual. After the surfaces of the specimens were free of roughness, prepolishing was performed with a diamond rubber brightener (OptraFine F). Fine polishing was performed with a very bright rubber polish (OptraFine $\mathrm{P}$ ).

Calculus and periodontal tissues on enamel and cementum surfaces were removed from the teeth using the cavitron device (Scalex 800, Dentamerica, California, USA). The shape of the cleaned teeth was thereafter modified to replicate the shape of the other antagonists with the help of diamond burs. After polishing (Prophet Paste, Sultan Chemist Inc., York, USA) and brushing (Stoddard, Hertfordshire, England) the cutting line is marked with a pen so that teeth are angled about 90 degrees below the level of the cervical line and cut with a diamond disc (Horico discs Diaflex F 358F, Horico Dental Hopf, Ringleb \& Co. GmbH \& Cie, Berlin, Germany).

Table 1 The materials used in this study

\begin{tabular}{|c|c|c|c|c|}
\hline Occlusal splint material & Code & Manufacturer & Composition & Lot no \\
\hline Sr Ivocap Heat Cured & SRI & Ivoclar Vivadent, Shaan, Liechtenstein & $\begin{array}{l}\text { Methyl Methacrylate } \\
\text { Ethylene Dimethacrylate }\end{array}$ & YC353P07 \\
\hline Valplast & VP & $\begin{array}{l}\text { Valplast International Corp., } \\
\text { Long Beach, NY, USA }\end{array}$ & Polyamide & $3009 A$ \\
\hline SR Ivocap Elastomer & SRE & Ivoclar Vivadent, Shaan, Liechtenstein & Methyl Methacrylate & YG072L04 \\
\hline Eclipse & EC & Dentsply International, York, PA & Urethane Oligomers & 070228 \\
\hline Antagonist material & Code & Manufacturer & Composition & Lot no \\
\hline inCoris TZI & $\mathrm{TZI}$ & SironaDental Systems, Bensheim, German & $\begin{array}{l}\text { Monoblock zirconia, } \mathrm{ZrO} 2+\mathrm{HfO} 2+\mathrm{Y} 2 \mathrm{O} 3(\geq 99.0) \\
\text { Y2O3 }(>4.5-\leq 6.0), \mathrm{HfO} 2(\leq 5), \mathrm{Al} 2 \mathrm{O} 3(\leq 0.5) \text {, Other } \\
\text { oxides }(\leq 0.5)\end{array}$ & $2,014,161,366$ \\
\hline IPS e.max Press & $\mathrm{IM}$ & Ivoclar Vivadent, Shaan, Liechtenstein & $\begin{array}{l}\text { Lithium disilicate glass-ceramic } \\
\mathrm{SiO}_{2}(57-80 \%) \mathrm{Li}_{2} \mathrm{O}(11-19 \%), \mathrm{K}_{2} \mathrm{O}(0-13 \%), \mathrm{P}_{2} \mathrm{O}_{5}(0-11 \%) \\
\mathrm{ZrO}_{2}(0-8 \%), \mathrm{ZnO}(0-8 \%), \text { other oxides and ceramic } \\
\text { pigments }\end{array}$ & U51802 \\
\hline Enamel & $\mathrm{E}$ & Maxillary Human third molar tubercle & $\begin{array}{l}96 \text { wt.\% inorganic material }\left(\mathrm{Ca}_{10}\left(\mathrm{PO}_{4}\right)_{6} \cdot 2(\mathrm{OH})\right) \text { and } \\
4 \text { wt.\% organic material and water }\end{array}$ & \\
\hline
\end{tabular}




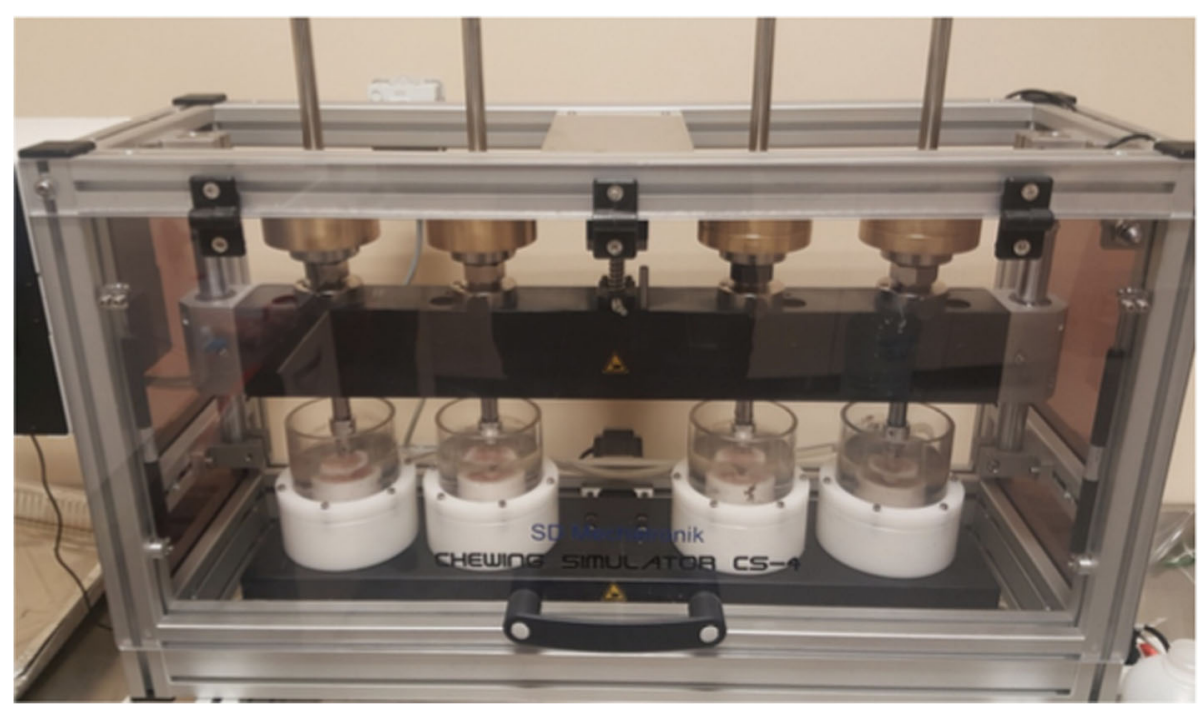

Fig. 1 Chewing Simulator CS-4 (SD Mechatronik GMBH, Feldkirchen-Germany)

All antagonist specimens were embedded in autopolymerizing acrylic resin (Technovit 4000; Heraeus Kulzer). The acrylic resin was mixed and poured in custom-made Teflon holders (Analitik Mühendislik, Gaziantep, Türkiye).

The wear test was performed using the Chewing Simulator CS-4 (Willytec/SD Mechatronik GmbH, FeldkirchenWesterham, Germany) as shown in Fig. 1. The simulator is a three-body wear machine, in which water or other conditions can be used with programmable $\left(5-55^{\circ} \mathrm{C}\right)$ thermocycling. The CS-4 can make gnashing, slipping, and striking movements with a $50-\mathrm{N}$ force when loaded with weight, for up to 120,000 cycles.

The specimens were prepared according the plastic specimen holders. Occlusal splint specimens were embedded in acrylic resin in the sub-specimen holder in the chewing simulator. The enamel, IPS e.max Press, and InCoris TZI $\mathrm{C}$ specimens were embedded in acrylic resin in the upper specimen holder for use as antagonist materials and fixed with fixing screws. All test groups to were subjected to a load of $50 \mathrm{~N}$.

The specimens were subjected to 30,000 loading cycles and each surface was analyzed after 10,000 cycles. Notably, 10,000 cycles are approximately equal to the maximum total number of chewing cycles experienced in 1 week by all-day splint users, and 2 weeks for night-time users, given the established range of 800-1400 chewing cycles per day [12]. A vertical load of $50 \mathrm{~N}$ was applied at a frequency of $1.6 \mathrm{~Hz}$. After vertical loading, horizontal movement of $2 \mathrm{~mm}$ was performed. Half of the specimens underwent an aging procedure in a dry condition. During wet aging, demineralized water at $30^{\circ} \mathrm{C}$ was used for continuous rinsing to remove the abraded particles from the sample (and to avoid any three-body wear processes) and to simulate the wet condition of the oral cavity. Owing to the uncertainty of the temperature used in other studies (temperatures of $25-37^{\circ} \mathrm{C}$ were used), the default temperature of the simulator was set at $30^{\circ} \mathrm{C}[9,10,13]$.

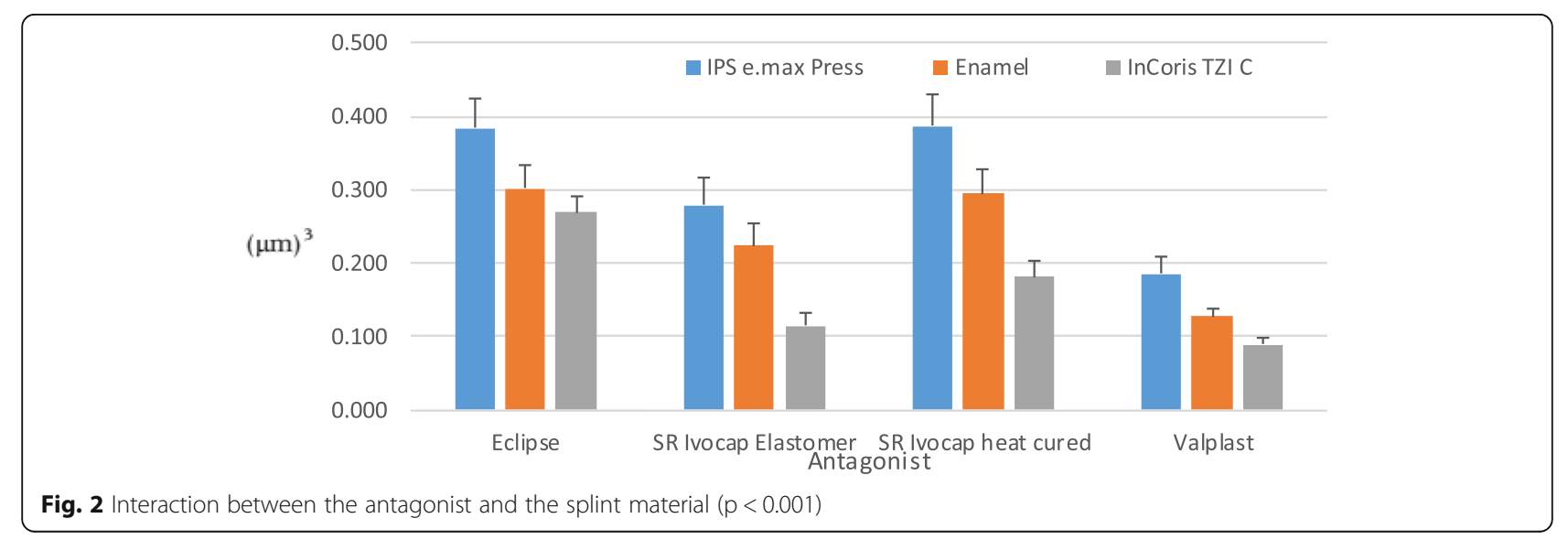




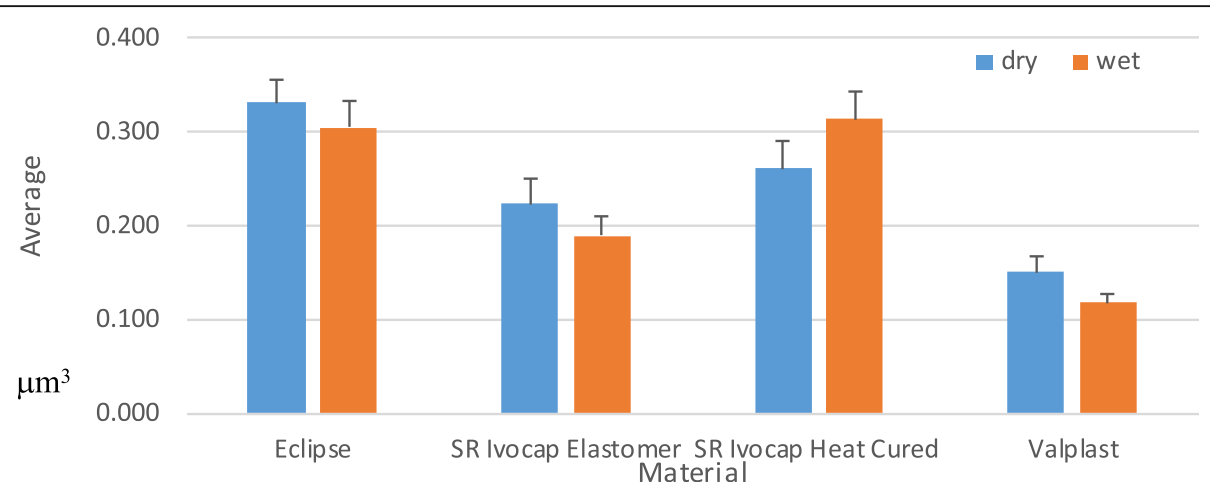

Fig. 3 Interaction between the splint material and conditions $(p=0.179)$

Each specimen was analyzed with a three-dimensional (3D) laser scanner (LAS-20, SD Mechatronik GMBH) and surface analysis program (Geomagic Control of 3D Systems; SD Mechatronik GMBH,) after removing it from the cyclic wear device.

The data were analyzed with IBM SPSS V23. Shapiro Wilk test was used for compatibility with normal distribution $(0,34,995,775)$. Both the main effects and interactions of Antagonist, material, cycle and environmental factors on average wear rates were investigated by Univariate variance analysis. Multiple comparisons were examined with the Games-Howell test. Analysis results are presented as arithmetic mean \pm standard error. Significance level was taken as $p<0.05$.

\section{Results}

There was a statistically significant effect of the difference in materials on the amount of wear $(p<0.001)$. Moreover, there was a statistically significant difference among the mean values of all materials. The highest mean value was obtained with Eclipse $0,318 \mu^{3}$, and the lowest mean value was obtained with Valplast 0 , $134 \mu^{3}$ as shown in Fig. 2. There was no statistically significant effect on the amount of wear for the wet and dry conditions $(p=0.179)$ as shown in Fig. 3.

The effect of the antagonist and material-to-material interaction on the amount of wear was statistically significant $(p<0.001)$.

The antagonist difference has a statistically significant effect on the amount of wear $(\mathrm{p}<0.001)$. When the antagonists were compared with each other, the difference between the 3 antagonists was found statistically significant. The lowest mean values were observed in the InCoris TZI C -Valplast interaction $\left(0,09 \mu \mathrm{m}^{3}\right)$. There was a difference between the average wear amount of the IPS e.max Press-Valplast interaction and the average values obtained with the interaction of IPS e.max Press with other materials $(p<0.001)$ as shown in Fig. 4.

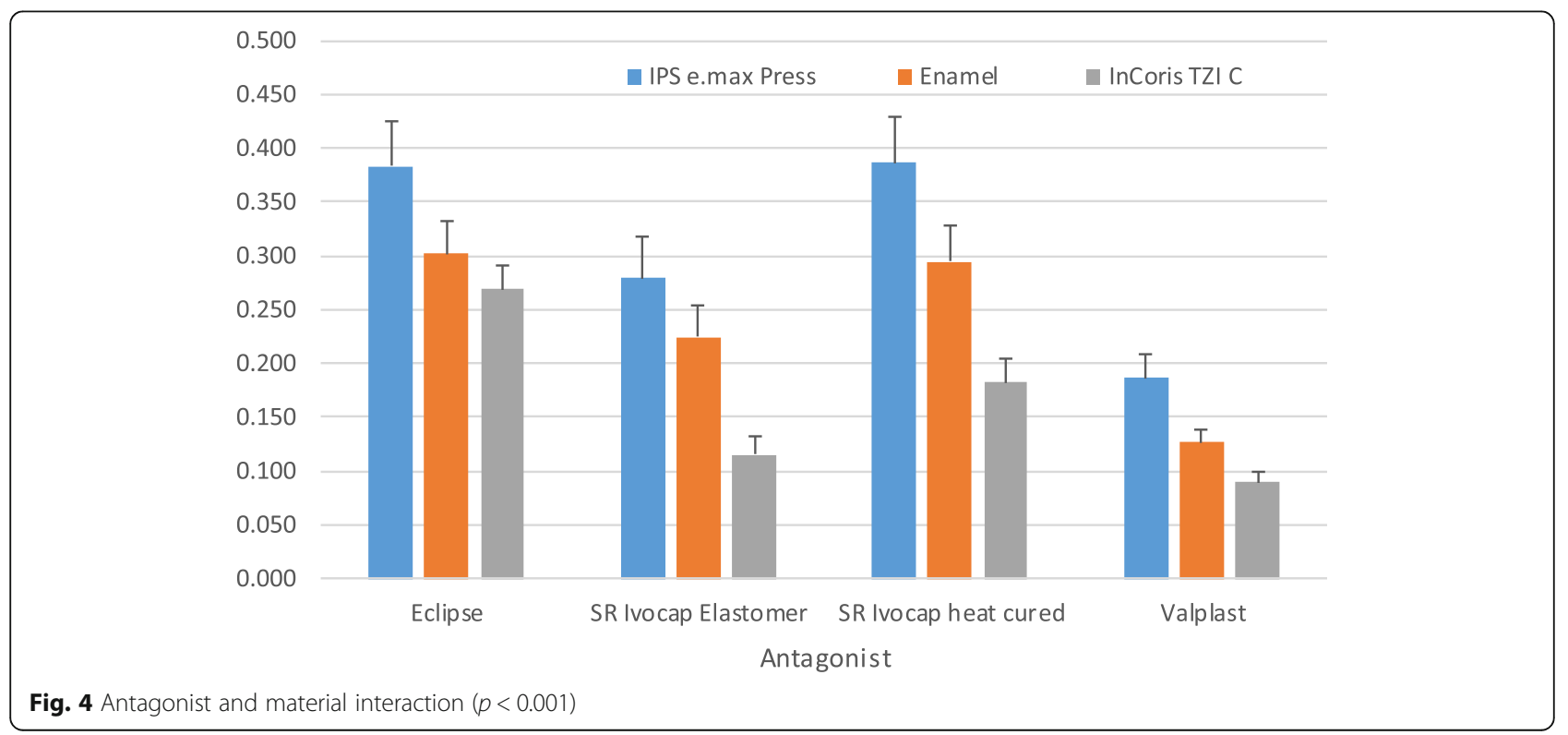




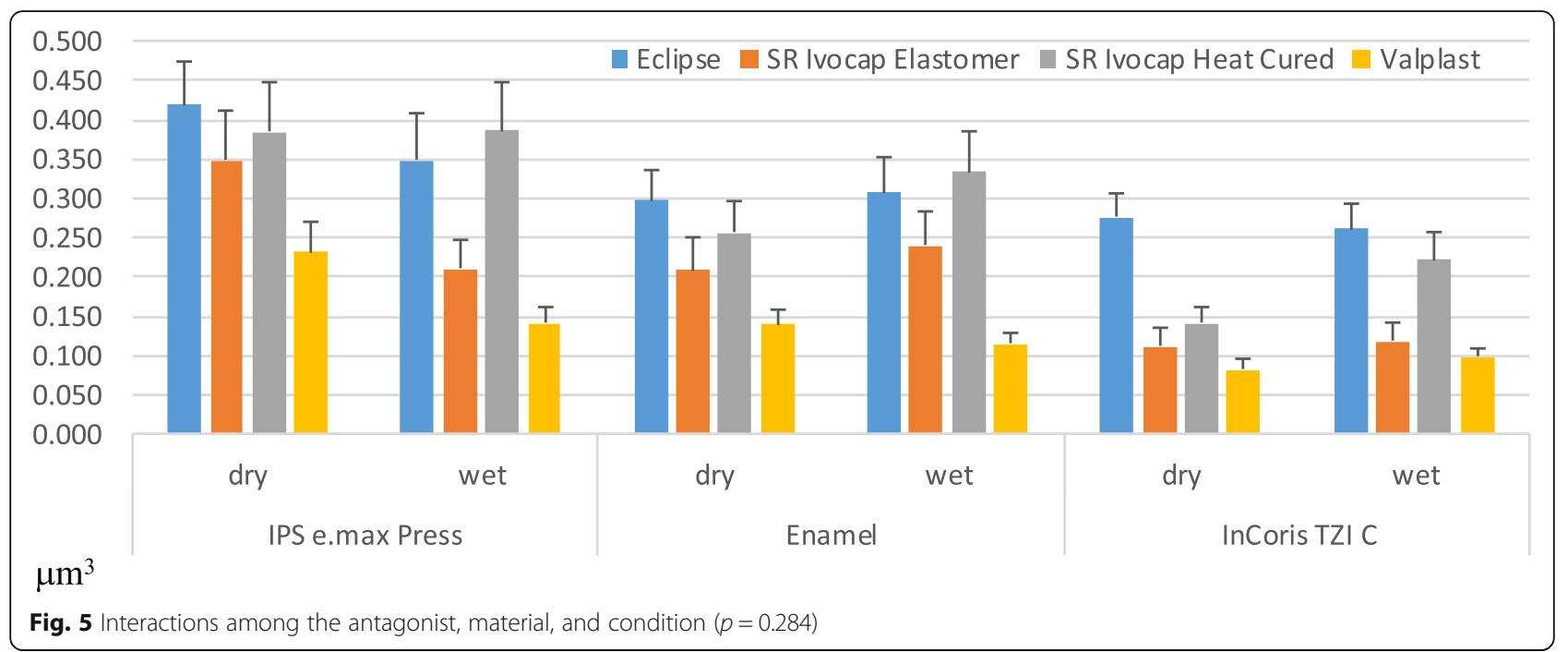

The effect of the antagonist, material, and condition interaction on the wear amounts was not statistically significant $(p=0.284)$ as shown in Fig. 5. The effect of the antagonist, material, cycle, and condition interaction on wear amount was statistically significant $(p<0.001)$. IPS e.max Press-Eclipse-(30,000 cycles, dry condition) interaction exhibited the highest mean value $\left(0,419 \mu \mathrm{m}^{3}\right)$ as shown in Fig. 6.

\section{Discussion}

The null hypothesis was rejected, according to the results of the study. Significant differences were observed between the groups based on type of occlusal splint material used.

The resistance of the splint materials to wear should therefore influence the choice of material that would meet the requirements of every patient. For example, a splint with greater durability is needed for a heavy bruxer, whose dentition is subjected to intense occlusal forces $[2,14]$. Besides, the study found differences in the in vitro wear resistance among various splint materials. This will ensure that each patient is provided an occlusal splint appliance based on his/ her masticatory load.

The wear process observed clinically is multifactorial and complex, which has been investigated by various research groups in vitro and in vivo [12, 14]. Wear-related laboratory simulations can only be used as a comparison for materials with the same wear behavior. Posterior composites have large differences in the in vivo and in vitro wear rates [8]. Efforts to correlate long-term in vitro results with those of in vivo conditions have not been very successful [15]. A study on wear reported that laboratory simulation methods could not predict clinical

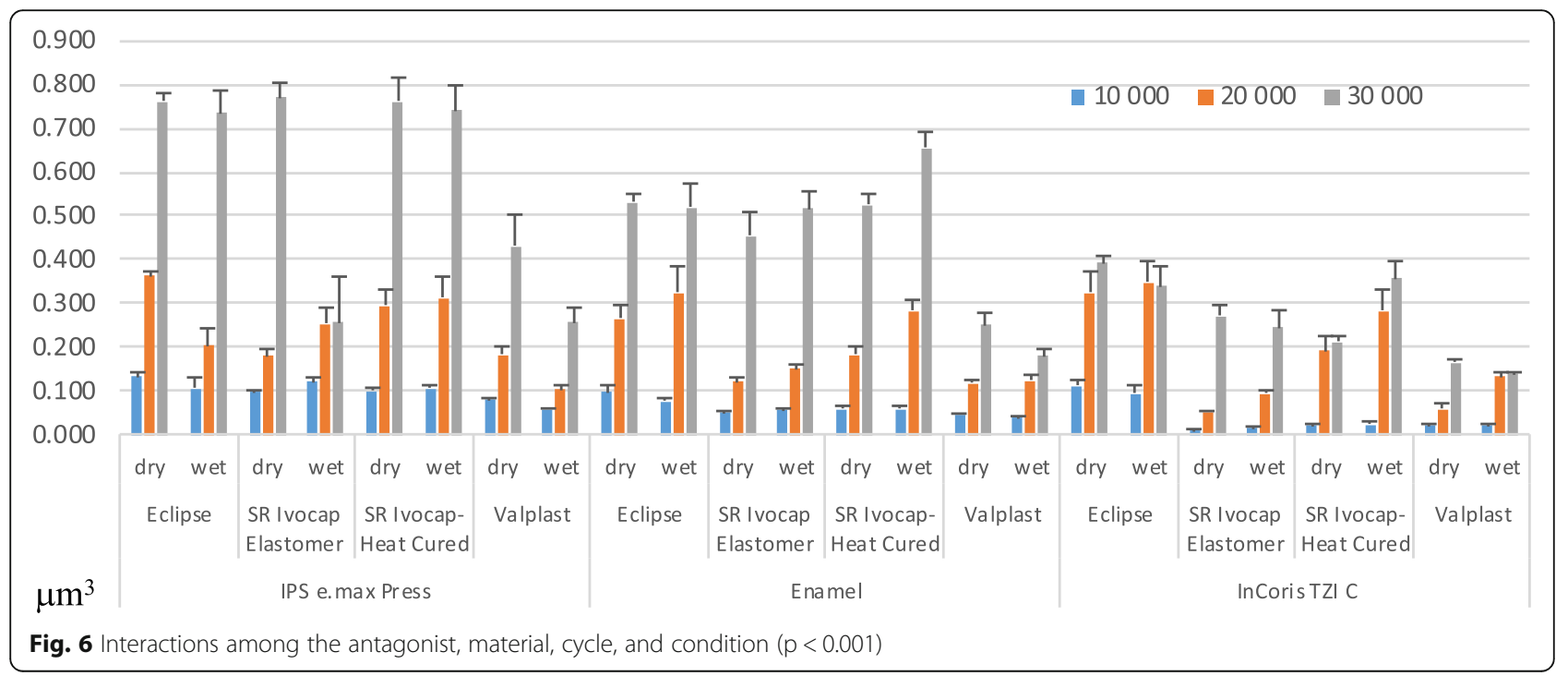


wear models, although they were useful for studying basic wear mechanisms [15].

The force used in this study was $50 \mathrm{~N}$, and 10,000, 20, 000 , and 30,000 cycles were used to determine the effect of the different number of cycles $[11,15,16]$. In previous studies, acrylic dentures were subjected to loads ranging from 13.5 and $50 \mathrm{~N}$ for $10,000-100,000$ cycles for evaluating the artificial acrylic and composite resin teeth teeth, and a force of $9.1 \mathrm{~kg}$ was used [8-10, 12].

Studies have been conducted to evaluate the wear characters of occlusal splint materials; however, a single standard antagonist has been used. There is only one study that also uses different antagonists, this study published in 2018 has shown that antagonist differences are also effective in determining wear character [17].

Heintze [4] tested different methods to measure the in vitro wear of dental materials. The three measurement principle, 3D laser, and mechanical and optical methods are suitable for quantifying the wear produced in flat specimens. Irrespective of the quantification method, both volume and vertical loss were highly correlated with each other, thus making it unnecessary to measure both variables for screening materials for wear resistance [4]. Other studies have also shown that the order of maximum height loss and wear volume is strongly correlated. In dentistry, maximum height loss is a clinically significant parameter because the vertical distance between the maxilla and mandible is stabilized by occlusal contact points [4].

Clinically, corrosive wear is unquestionably an important aspect of occlusal splint materials. Alcohol plasticizes resins, water causes filler leaching, and certain microorganisms produce esterase enzymes that can degrade resin [18]. A limitation of this study was that the corrosive aspect of wear was not investigated. Future studies should investigate the wear process of occlusal splint materials when exposed to exogenous chemical substances that are commonly found in the diet.

\section{Conclusions}

The findings from this study would enable clinicians to make more reliable choices regarding the occlusal splint material that is best suited for each patient. The antagonist type had a statistically significant effect on occlusal splint wear. There were differences in the in vitro wear resistance among various splint materials.

\section{Supplementary information}

Supplementary information accompanies this paper at https://doi.org/10. 1186/s12903-020-01165-9.

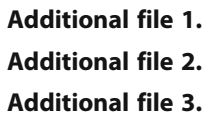

\section{Abbreviations}

TMD: Temporomandibular joint disorders; 3D: Three-dimensional

Acknowledgements

Not applicable.

\section{Declarations}

The authors have no conflict of interest with the companies whose materials were mentioned in present study.

\section{Authors' contributions}

KYD carried out the preparation of all samples and antagonists in the study, made the wear tests in the chewing simulator and scanning samples in the 3D scanner. She also worked with YUA to determine the data and evaluate it in the surface analysis program. All of the authors contributed to the writing of the article. The authors read and approved the final manuscript.

* Department of Prosthodontics, Dentistry Faculty, University of Marmara,

Basibuyuk, Maltepe, Istanbul, Turkey.

\section{Funding}

This study was funded by the Marmara University Scientific Research Commission. All documents sent to Springer Nature waivers team (01.Apr.2020).

Availability of data and materials

All documents attached as a supplementary document.

Ethics approval and consent to participate

Not applicable.

Consent for publication

Not applicable.

\section{Competing interests}

Not applicable.

Received: 3 April 2020 Accepted: 15 June 2020

Published online: 22 June 2020

\section{References}

1. Liu F, Steinkeler A. Epidemiology, diagnosis, and treatment of temporomandibular disorders. Dent Clin N Am. 2013;57(3):465-79.

2. Okeson JP, Moody PM, Kemper JT, Haley JV. Evaluation of occlusal splint therapy and relaxation procedures in patients with temporomandibular disorders. J Am Dent Assoc. 1983;107(3):420-4.

3. Lambrechts P, Braem M, Vuylsteke-Wauters M, Vanherle G. Quantitative in vivo wear of human enamel. J Dent Res. 1989;68(12):1752-4.

4. Heintze SD. How to qualify and validate wear simulation devices and methods. Dent Mater. 2006;22(8):712-34.

5. Kato K, Adachi K. Wear of advanced ceramics. Wear. 2002;253(11-12):1097104.

6. D'Arcangelo C, Vanini L, Rondoni GD, De Angelis F. Wear properties of dental ceramics and porcelains compared with human enamel. J Prosthet Dent. 2016;115(3):350-5.

7. Heintze SD, Albrecht T, Cavalleri A, Steiner M. A new method to test the fracture probability of all-ceramic crowns with a dual-axis chewing simulator. Dent Mater. 2011;27(2):e10-9.

8. Hahnel S, Behr M, Handel G, Rosentritt M. Two-body wear of artificial acrylic and composite resin teeth in relation to antagonist material. J Prosthet Dent. 2009;101(4):269-78.

9. Stober T, Henninger M, Schmitter M, Pritsch M, Rammelsberg P. Three-body wear of resin denture teeth with and without nanofillers. J Prosthet Dent. 2010;103(2):108-17.

10. Schulte JK, Anderson GC, Sakaguchi RL, DeLong R. Wear resistance of isosit and polymethyl methacrylate occlusal splint material. Dent Mater. 1987;3(2): 82-4.

11. Casey J, Dunn WJ, Wright E. In vitro wear of various orthotic device materials. J Prosthet Dent. 2003;90(5):498-502.

12. Lambrechts P, Debels E, Van Landuyt K, Peumans M, Van Meerbeek B. How to simulate wear? Overview of existing methods. Dent Mater. 2006;22(8): 693-701. 
13. Sakaguchi RL, Douglas WH, DeLong R, Pintado MR. The wear of a posterior composite in an artificial mouth: a clinical correlation. Dent Mater. 1986;2(6): 235-40.

14. Mair LH, Stolarski TA, Vowles RW, Lloyd CH. Wear: mechanisms, manifestations and measurement. Report of a workshop. J Dent. 1996;24(12):141-8.

15. Issar-Grill N, Roberts HW, Wright EF, Dixon SA, Vandewalle KS. Volumetric wear of various orthotic appliance materials. Cranio. 2013;314(4):270-5.

16. Kurt H, Erdelt KJ, Cilingir A, Mumcu E, Sulun T, Tuncer N, et al. Two-body wear of occlusal splint materials. J Oral Rehabil. 2012;39(8):584-90.

17. Reyes-Sevilla M, Kuijs RH, Werner A, Kleverlaan CJ, Lobbezoo F. Comparison of wear between occlusal splint materials and resin composite materials. J Oral Rehabil. 2018:45(7):539-44.

18. Hammouda IM. Effect of light-curing method on wear and hardness of composite resin. J Mech Behav Biomed Mater. 2010;3(2):216-22.

\section{Publisher's Note}

Springer Nature remains neutral with regard to jurisdictional claims in published maps and institutional affiliations.

Ready to submit your research? Choose BMC and benefit from:

- fast, convenient online submission

- thorough peer review by experienced researchers in your field

- rapid publication on acceptance

- support for research data, including large and complex data types

- gold Open Access which fosters wider collaboration and increased citations

- maximum visibility for your research: over $100 \mathrm{M}$ website views per year

At BMC, research is always in progress.

Learn more biomedcentral.com/submissions 